\title{
Pancreatic Gastrointestinal Stromal Tumour: A Case Report and Review of the Literature
}

\author{
Daadoucha Abderrahmen 1*, Farhat Waad², Ben Mabrouk Mohamed ${ }^{2}$, Harrabi Fathia', \\ Azzaza Mohamed², Ben Ali Ali ${ }^{2}$
}

${ }^{1}$ Department of Medical Imaging, Ibn Al Jazzar University Hospital, Kairouan, Tunisia

${ }^{2}$ Department of Digestive Surgery, Sahloul University Hospital, Sousse, Tunisia

Email: *dr.daadoucha@yahoo.fr

How to cite this paper: Abderrahmen, D., Waad, F., Mohamed, B.M., Fathia, H., Mohamed, A. and Ali, B.A. (2017) Pancreatic Gastrointestinal Stromal Tumour: A Case Report and Review of the Literature. Journal of Cancer Therapy, 8, 954-961. https://doi.org/10.4236/jct.2017.811085

Received: August 17, 2017

Accepted: November 20, 2017

Published: November 23, 2017

Copyright () 2017 by authors and Scientific Research Publishing Inc. This work is licensed under the Creative Commons Attribution International License (CC BY 4.0).

http://creativecommons.org/licenses/by/4.0/

\begin{abstract}
Gastrointestinal stromal tumours (GIST) are rare mesenchymal neoplasms that can develop in the entire length of the gastrointestinal tract or sometimes from the omentum and mesentery. In most cases, they arise from the stomach, less often the jejunum or ileum. We report the case of a 53-year-old-female patient, without significant medical history, consulting for chronic epigastric pain, with no other associated signs. She had underwent an abdominal ultrasound completed with a Contrast-enhanced computed tomography (CT) of the abdomen showing a large tissular mass developed at the expense of the cephalic portion of the pancreas, with central calcifications and heterogeneous enhancement after contrast injection. Pancreaticoduodenectomy, partial colectomy and antrectomy has been performed and histological examination with immunohistochemical study had concluded the diagnosis of pancreatic primary GIST.
\end{abstract}

\section{Keywords}

Stromal Tumor, Pancreas, Imaging, Histopathology

\section{Introduction}

Although rare ( $1 \%$ of the digestive tract malignant tumors), gastrointestinal stromal tumors are the most common mesenchymal neoplasms of the gastro intestinal tract. They represent a particular pathological entity [1] [2]. They were individualized by Mazur and Clark in 1983 [3] and were distinguished in 1988 from other mesenchymal tumors (leiomyoma, leiomyosarcoma, schwannoma...) [4] by the discovery of a mutated receptor of a tyrosine kinase expressed on the surface of tumoral cells: C-Kit or CD117 whose immunohistochemical detection 
is the main criteria of diagnosis GISTs [3]-[8].

GIST are believed to be arisen from, or differentiating along, the interstitial cells of Cajal (ICCs) also called "interstitial neural cells" or "intestinal pacemaker cells" and recent studies postulate that GIST arise from multipotential mesenchymal stem cells. Their malignant potential is variable depending on the tumor size and number of mitosis [9] [10].

\section{Patient and Observation}

A 53-year-old woman consulted with non-specific epigastric pain for several months. There were no other associated signs especially fever, jaundice, vomiting, or gastrointestinal bleeding. Physical exam revealed a mobile epigastric mass associated with localised tenderness. The patient had a good performance status with a zero on the WHO Performance status score. Abdominal ultrasound showed the presence of a large, lobulated, circumscribed $11.6 \times 10.5 \times 9.5 \mathrm{~cm}$ mass developed at the expense of the cephalic portion of the pancreas. The echogenicity was heterogeneous with a central focus of micro-calcifications and hypo echoic liquid areas (Figure 1).

CT scan, performed with oral and intravenous contrast, upheld the findings of ultrasound revealing a large heterogeneous tissular mass in the pancreatic head, with central necrosis and calcifications (Figure 2). It showed an intense heterogeneous enhancement in the arterial phase. This mass was bounded in front by the gall bladder which is repressed, in the back by the right kidney with apparent para renal fat invasion and laterally, by digestive structures (small bowl and colon). The corporeal and caudal portions of the pancreas were normal. Moreover, intrahepatic and extrahepatic bile ducts were not dilated and no metastatic localisation was detected.

The patient underwent a hemipancreaticoduodenectomy with antrectomy and partial colectomy. Macroscopic histological examination of the surgical specimen showed a yellowish well circumscribed and unencapsulated mass measuring

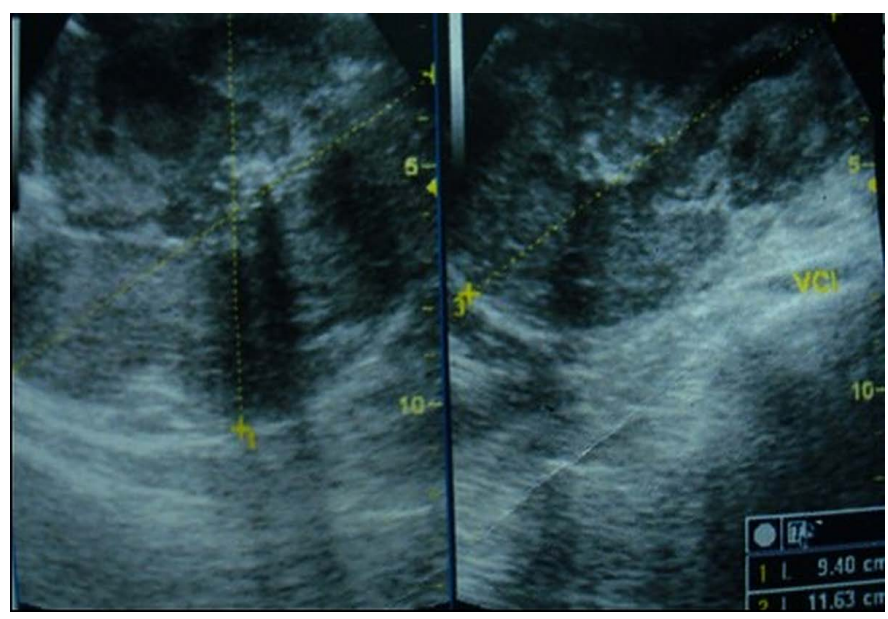

Figure 1. Ultra sounds: heterogeneous mass containing central calcifications. 
$10.5 \mathrm{~cm}$ (Figure 3).

On microscopic examination, there was a proliferation of spindle and epithelioid cells with a mitotic index of 6 mitoses/50 high power fields (Figure 4). No invasion of surrounding digestive structures was objectified. Tumour cells' Immunohistochemical study had come back positive to CD117 (C-kit) and CD34 and negative to smooth muscle actin, S100 protein, synaptophysin and cytokeratin (Figure 5). The diagnosis of pancreatic primary GIST with high malignant potential was made.

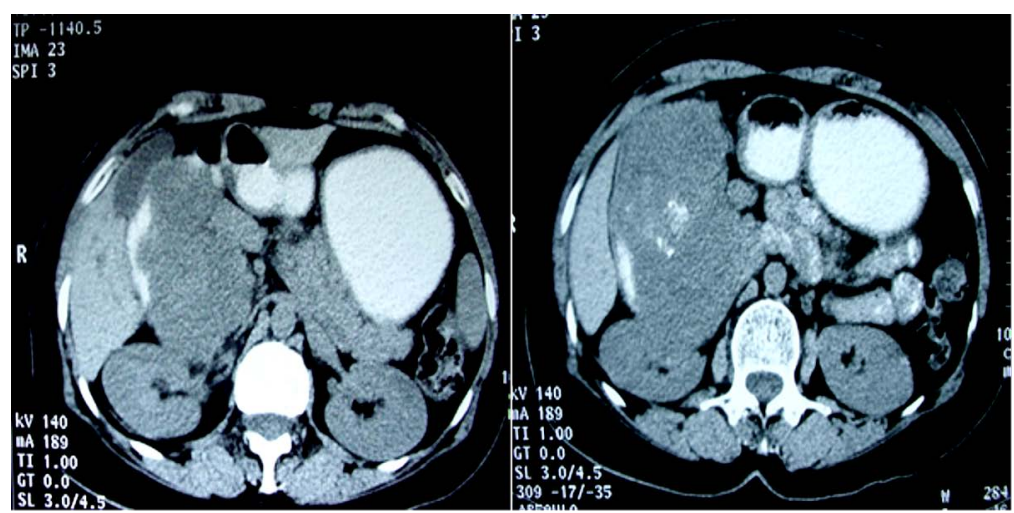

(a)

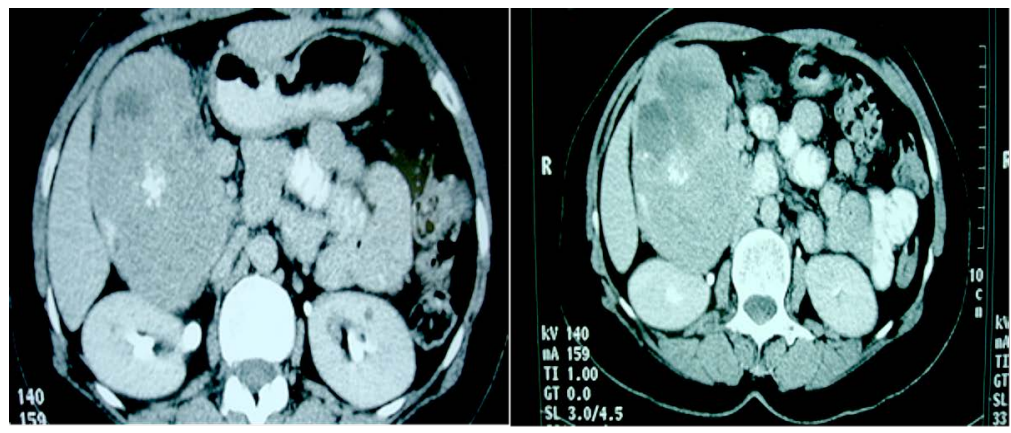

(b)

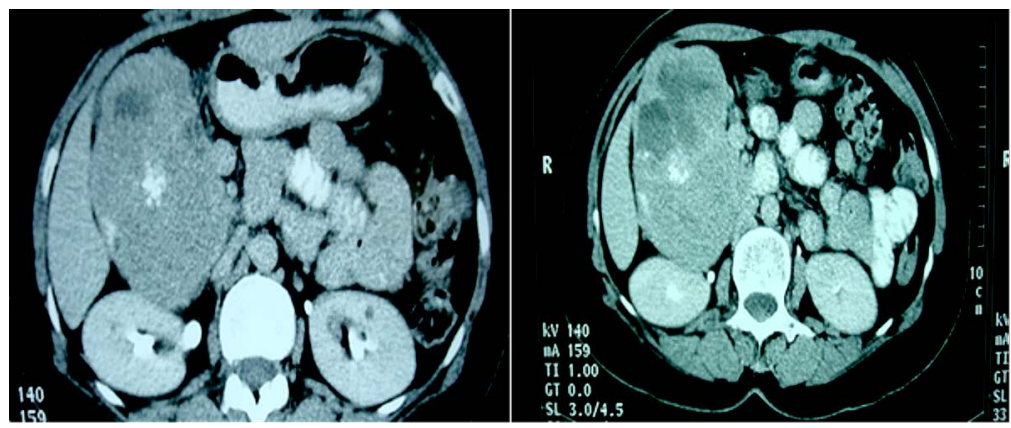

(c)

Figure 2. Abdominal computed tomography scan. (a) Computed tomography scan with oral contrast showing the calcifications within the pancreatic head mass which is repressing the gall bladder; (b) Computed tomography scan performed after oral and venous contrast in the portal phase showing an intense heterogeneous enhancement associated with necrosis within the mass; (c) Computed tomography scan performed after oral and venous contrast in the tardive phase. 


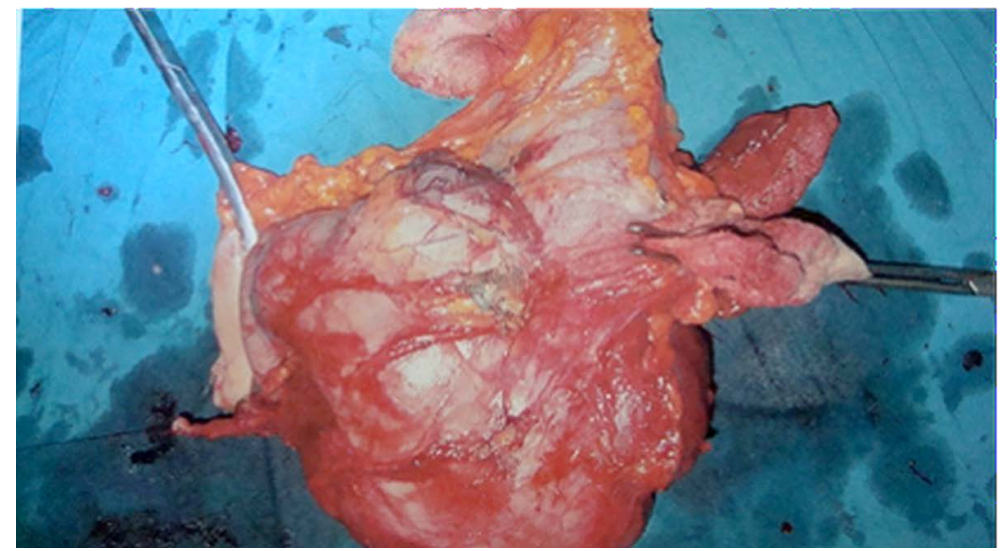

Figure 3. Surgical specimen.

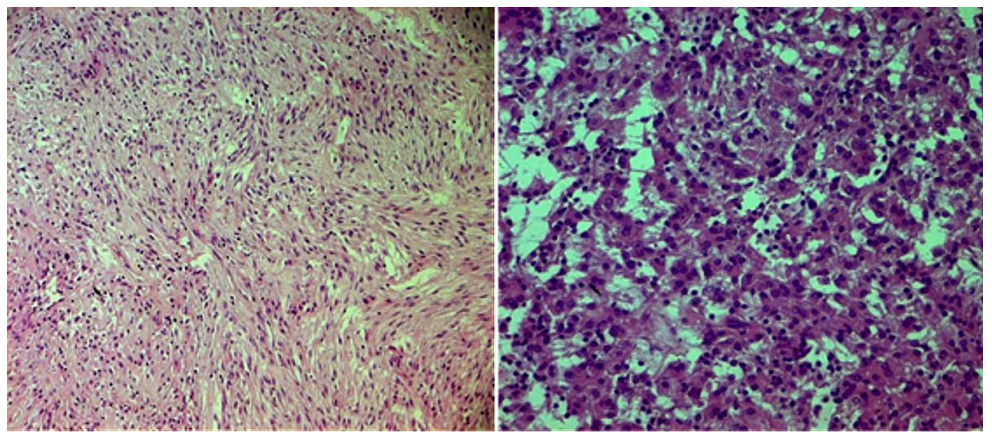

Figure 4. Microscopic examination HE stain: epithelioid and spindle cells.

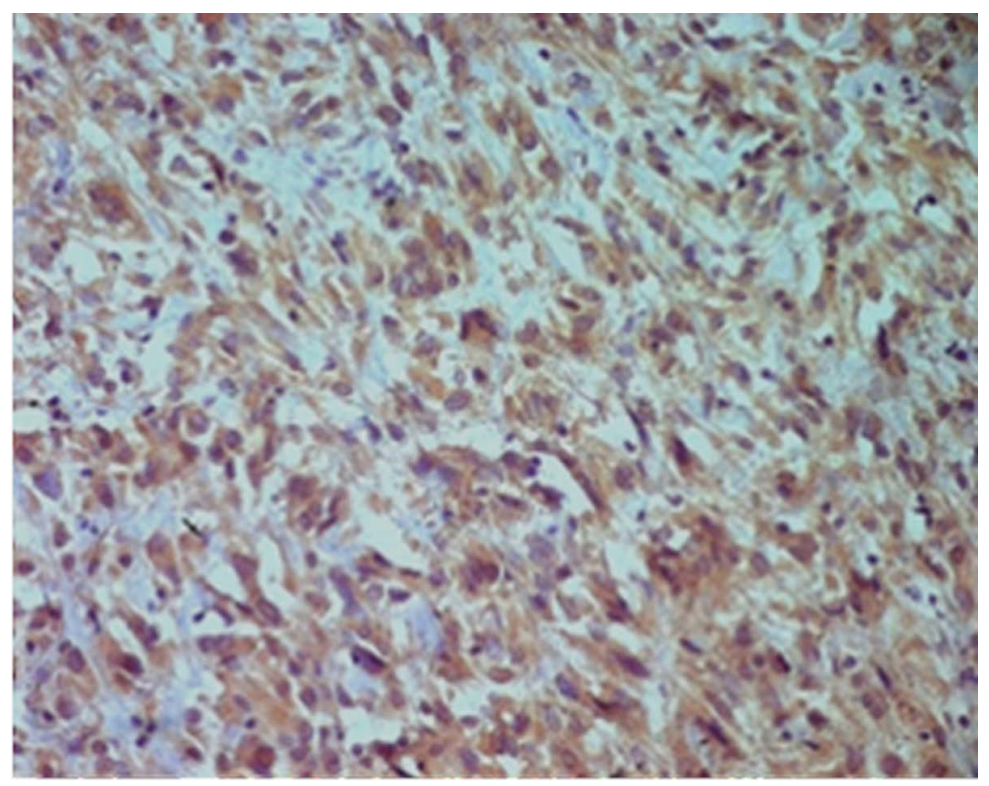

Figure 5. Positivity of tumor cells for CD117 in the immunohistochemical examination.

The two-year follow-up of the patient revealed the appearance of secondary metachronous liver metastases on CT and confirmed by liver MRI (Figure 6). The patient was put on Glivec and is set to undergo a close follow up with 


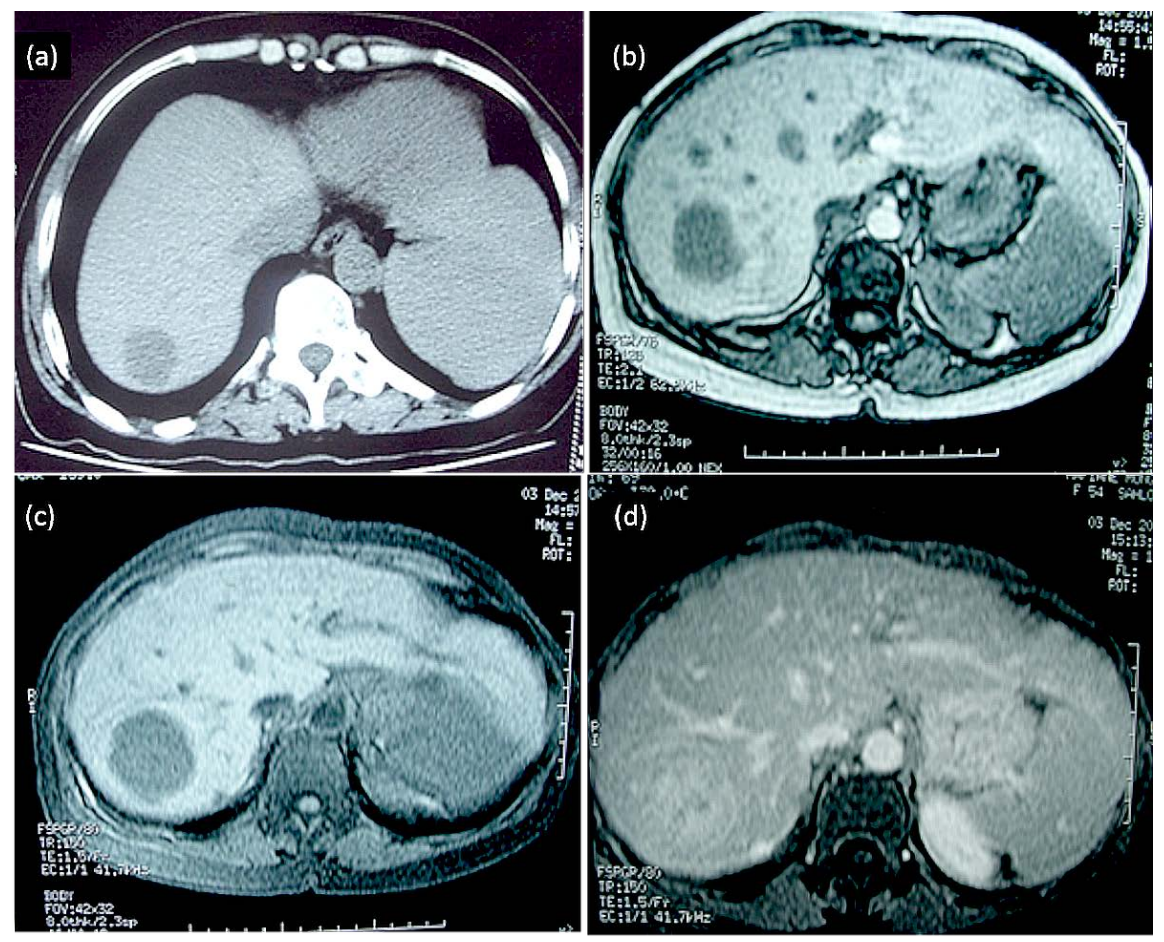

Figure 6. CT and MRI images through the liver showing secondary metachronous liver metastasis.

possible surgical metastasectomy.

\section{Discussion}

Pancreatic location of gastrointestinal stromal tumors is extremely rare [11] [12] [13] [14]. Only a few cases have been reported around the world to our knowledge. GIST are believed to be arisen from, or differentiating along, the interstitial cells of Cajal [4] these cells are usually located between the autonomous myenteric nerve plexus and smooth muscle cells of the bowel wall which explains their usual gastrointestinal location. [4] [15].

Somatic mutations of the c-kit gene are the cause of most sporadic GISTs. The c-kit is a Trans membrane receptor protein of growth factor (stem cell factor) having a tyrosine kinase activity. The mutation causes a gain of function resulting in activation of the tyrosine kinase activity independently to the attachment to its ligand. It follows a cascade of activator signals in the cell having a proliferative effect [16]. Yammato et al. report that GISTs' extra gastrointestinal location and the typical GISTs have in common the mutation of C-kit, suggesting that they have the same cellular origin [17].

The origin of primitive gastrointestinal stromal tumours of the pancreas have been the subject of recent studies that have demonstrated the existence of interstitial cells of Cajal in human exocrine pancreas which may explain the possibility of pancreatic origin of the primitive GISTs [18].

The expression of CD117 or C-kit is the main diagnostic criterion of these tumors; however other immunohistochemical markers allowed distinguishing 
GISTs from other mesenchymal tumors S100 protein to schwannomas, smooth muscle actin and desmin for smooth muscle tumors such as leiomyomas and leiomyosarcomas. [8].

These tumours have varying degrees of malignancy [9], it is presently considered that gastrointestinal stromal tumour is malignant if it is larger than $5 \mathrm{~cm}$ and if the mitotic count is greater than five mitoses per 50 fields. Beyond $50 \mathrm{mi}-$ toses per 50 fields, the tumor is said to be high grade [19]. In our case, the tumor was listed high malignant potential based on these criteria. The clinical expression of GISTs depends on their location and size. [20] In our case, the mode of revelation was merely vague epigastric pain and drawling, this same mode of revelation was found in two cases among those reported in the literature. The other cases were revealed by abdominal pain, nausea, feeling tired and finally two cases discovered incidentally on imaging have been reported [21].

Imaging is essential in the assessment of these tumors. CT is the main procedure, performed before and after intravenous and oral contrast, it can suggest the diagnosis, specify the staging, guides biopsies, post-therapeutic follow up [22] for both surgical and systemic treatment. it typically shows a large, highly enhancing mass on contrast CT scans often heterogeneous because of necrosis, haemorrhage or cystic degeneration [22]. MRI is reserved for pre-surgical study of pelvic localisations since it allows a more efficient analysis of tissue structures that the scanner [9] [10] and thus has less interest in pancreatic locations. Most metastasises are hepatic and peritoneal. Lymph node and bone pulmonary secondary locations are rare. [8] [22].

The appearance of GISTs in CT can be correlated to the degree of malignancy: when benign, they are often small and homogeneous well circumscribed, presenting a moderate enhancement after systemic contrast administration [23]. Aggressive GISTs are often "bulky" with intense heterogeneous enhancement with central necrosis [23]. Areas of Intra-tumoral haemorrhage can be found. The presence of calcifications is classic but unusual. [3] [8] [16].

\section{Conclusion}

Radiological findings in our case match aggressive GISTs features. Pancreatic GISTs, although rare, raise a differential diagnosis problem with pancreatic masses especially hyper vascular tumors. This diagnosis although difficult should be mentioned on the imaging characteristics in the absence of evocative context of other pancreatic tumors [20].

\section{Competing Interests}

The authors declare no competing interest.

\section{Authors' Contributions}

Abderrahmen Daadoucha: substantial contributions to conception and design, acquisition of data, or analysis and interpretation of data; 2) drafting the 
article or revising it critically for important intellectual content

Mohamed Amine Krichen: substantial contributions to conception and design, acquisition of data, or analysis and interpretation of data; 2) drafting the article or revising it critically for important intellectual content

Mohamed Ben Mabrouk: final approval of the version to be published.

\section{References}

[1] Yan, B.M., Pai, R.K. and Van Dam, J. (2008) Diagnosis of Pancreatic Gastrointestinal Stromaletumor by EUS Guided FNA. JOP, 9, 192-196.

[2] Mazur, M.T. and Clark, H.B. (1983) Gastric Stromaletumors. Reappraisal of Histogenesis. The American Journal of Surgical Pathology, 7, 507-519. https://doi.org/10.1097/00000478-198309000-00001

[3] Bassou, D., Darbi, A., Harket, A., Chamssi, M., et al. (2008) Tumeur Stromale Digestive: Apport du scanner et corrélations pathologiques. Feuillets de Radiologie, 48, 39-44. https://doi.org/10.1016/S0181-9801(08)70318-X

[4] Landi, B., Lecomte, T., Berger, A. and Cellier, C. (2004) Clinical Management of Gastrointestinal Stromal Tumors. Gastroenterologie Clinique et Biologique, 28, 893 901. https://doi.org/10.1016/S0399-8320(04)95154-8

[5] Handra-Luca, A., Nahon, P., Fléjou, J.F., Molas, G, et al. (2001) Immunohistochemical and Ultrastructural Heterogeneity of Gastrointestinal Stromal Tumors. Gastroenterologie Clinique Et Biologique, 25, 664-668.

[6] Montemurroa, M., Dirnhoferb, S. and Bornerc, M. (2008) Recommendations for the Diagnosis, Treatment, and Monitoring of Patients with Gastrointestinal Stromal Tumor. Forum Médical Suisse, 8, 544-549.

[7] De Mestier, Ph. and des Guetz, G. (2003) Treatment of Gastrointestinal Stromal Tumors with Imatinib: A Major Breakthrough in the Understanding of the Tumor-Specific Molecular Characteristics. E-Mémoires de IAcadémieNationale de Chirurgie, 2, 48-52.

[8] Lau, S., Tama, K.F., Kama, C.K., Luia, C.Y., et al. (2004) Imaging of Gastrointestinal Stromale Tumour (GIST). Clinical Radiology, 59, 487-498. https://doi.org/10.1016/j.crad.2003.10.018

[9] Taieb, S., Ceugnart, L., Bonodeau, F., Vanseymortier, L., et al. (2008) GIST: Imaging Findings. Journal De Chirurgie, 145, 6S12-6S17.

[10] Blay, J.Y., Landi, B., Bonvalot, S., Monges, G., et al. (2005) Recommendations for the Management of GIST Patients. Bulletin du Cancer, 92, 907-918.

[11] Daum, O., Klecka, J., Ferda, J., Treska, V., et al. (2005) Gastrointestinal Stromaletumor of the Pancreas: Case Report with Documentation of KIT Gene Mutation. Virchows Archiv, 446, 470-472. https://doi.org/10.1007/s00428-004-1200-4

[12] Harindhanavudhi, T., Tanawuttiwat, T., Pyle, J. and Silva, R. (2009) Extra-Gastrointestinal Stromal Tumor Presenting as Hemorrhagic Pancreatic Cyst Diagnosed by EUS-FNA. Journal of the Pancreas, 10, 189-191.

[13] Showalter, S.L., Lloyd, J.M., Glassman, D.T. and Berger, A.C. (2008) Extra-Gastrointestinal Stromal Tumor of the Pancreas Case Report and a Review of the Literature. Archives of Surgery, 143, 305-308. https://doi.org/10.1001/archsurg.2007.68

[14] Neto, M.R., Machuca, T.N., Pinho, R.V., Yuasa, L.D., et al. (2004) Gastrointestinal Stromaletumor: Report of Two Unusual Cases. Virchows Archiv, 444, 594-596. https://doi.org/10.1007/s00428-004-1009-1 
[15] Rejchrt, S., Tycova, V. and Bures, J. (2005) Tumeursstromales Gastro-Intestinales (GIST). Acta Endoscopica, 35, 195-206. https://doi.org/10.1007/BF03009104

[16] Rangheard, A.S., Lazure, T., Dimet, S., Bessoud, B., et al. (2005) Tumeur Stromale Gastro-Intestinale. Feuillets de Radiologie, 45, 451-455.

[17] Yamamoto, H., Oda, Y., Kawaguchi, K., Nakamura, N., et al. (2004) C-Kit and PDGFRA Mutations in Extragastrointestinal Stromal Tumor (Gastrointestinal Stromal Tumor of the Soft Tissue). The American Journal of Surgical Pathology, 28, 479-488. https://doi.org/10.1097/00000478-200404000-00007

[18] Popescu, L.M., Hinescu, M.E., Ionescu, N., Ciontea, S.M., et al. (2005) Interstitial Cells of Cajal in Pancreas. Journal of Cellular and Molecular Medicine, 9, 169-190. https://doi.org/10.1111/j.1582-4934.2005.tb00347.x

[19] Miettinen, M. and Lasota, J. (2001) Gastrointestinal Stromaletumors: Definition, Clinical, Histological, Immunohistochemical, and Moleculargenetic Features and Differential Diagnosis. Virchows Archiv, 438, 1-12. https://doi.org/10.1007/s004280000338

[20] Boyer, C., Duvet, S., Wacrenier, A., Toursel, H., et al. (2001) Leiomyosarcoma and Stromal Tumor of the Pancreas. Journal of Radiology, 82, 1723-1725.

[21] Padhi, S., Kongara, R., Uppin, S.G., Uppin, M.S., et al. (2010) Extragastrointestinal Stromal Tumor Arising in the Pancreas: A Case Report with a Review of the Literature. JOP, 11, 244-248.

[22] Hong, X., Choi, H., Loyer, E.M., Benjamin, R.S., et al. (2006) Gastrointestinal Stromal Tumor: Role of CT in Diagnosis and in Response Evaluation and Surveillance after Treatment with Imatinib. Radiographics, 26, 481-495.

https://doi.org/10.1148/rg.262055097

[23] Huang, Z., Li, Y., Zhao, H., Zhao, J.J., et al. (2013) Prognositic Factors and Clinicopathologic Characteristics of Small Gastrointestinal Stromal Tumor of the Stomach: A Retrospective Analysis of 31 Cases in One Center. Cancer Biology \& Medicine, 10, 165-168. 